\title{
Study of vertical transmission of COVID-19 infection in COVID-19 positive obstetrical patients by comparing amniotic fluid and immediate neonatal COVID-19 RT-PCR
}

\author{
Smita Tyagi ${ }^{1}$, Rajesh Kumar Agarwal ${ }^{2 *}$, Manish Agrawal $^{3}$, Manika Kapoor ${ }^{3}$, Sakshi Tiwari ${ }^{3}$ \\ ${ }^{1}$ Department of Obstetrics and Gynecology, Muzaffarnagar Medical College, Muzaffarnafar, Uttar Pradesh, India \\ ${ }^{2}$ Department of Pathology, Subharti Medical College, Meerut, Uttar Pradesh, India \\ ${ }^{3}$ Department of Paediatrics, Muzaffarnagar Medical College, Muzaffarnagar, Uttar Pradesh, India
}

Received: 18 July 2021

Accepted: 09 August 2021

\section{*Correspondence:}

Dr. Rajesh Kumar Agarwal,

E-mail: agarwal_r_k2003@gmail.com

Copyright: $\odot$ the author(s), publisher and licensee Medip Academy. This is an open-access article distributed under the terms of the Creative Commons Attribution Non-Commercial License, which permits unrestricted non-commercial use, distribution, and reproduction in any medium, provided the original work is properly cited.

\begin{abstract}
Background: The objective of this study was to estimate the incidence of vertical transmission COVID-19 by RT-PCR. Methods: In this hospital based prospective study, all COVID-19 positive pregnant women admitted in COVID ward in Muzaffarnagar medical college and hospital from April 2020 to January 2021 were included. A detailed history and examination was done and all routine investigations were done as per protocol. Samples were taken from amniotic fluid during vaginal delivery or caesarean section and collected in viral transport medium. Sample were also collected as nasal and oropharyngeal swab from neonate immediately after birth and sent for COVID 19 RT-PCR.

Results: Out of total 50 cases; $43(86 \%)$ neonates were delivered via LSCS and $7(14 \%)$ by normal delivery, out of these $41(82 \%)$ neonates were normal; 4 (8\%) were IUGR, $2(4 \%)$ were IUD, $2(4 \%)$ were pre-term and $1(2 \%)$ neonatal death. All 50 amniotic fluid as well as nasal and oropharyngeal samples of all neonates were negative by RT-PCR.

Conclusions: Low vertical transmission may be due to the fact that antibodies are produced by mother that crosses the placenta and saves the fetus or there are highly specific immunological mediators in the placenta that do not allow the infection to pass to the fetus.
\end{abstract}

Keywords: COVID-19, Vertical transmission, Amniotic fluid, RT-PCR

\section{INTRODUCTION}

History is repeating itself in the form of pandemic every 100 years. 1819 was plague pandemic, 1919 after 100 years was Spanish flu pandemic and 2019 (after 100 years) is corona virus pandemic. It has come as a disaster in public health emergency system.

Because of its high infectivity and high mortality various new health protocols were made like PPE kits, N19 mask, goggles and face shields to fight this disease because for the first time in the history of mankind, even the doctors who were treating the patients had high mortality rate. This all was because of the unknown pathogenesis and hence no guidelines for the treatment of this disease in initial stages.
Whole world was affected and everybody was seeking measures to protect themselves from the disease. ${ }^{1}$

But how can an unborn fetus in-utero can protect himself, so this study was done to know about the antenatal transmission of disease from mother to fetus so that necessary measure so that necessary measures can take place to save the fetus.
Aim
The aim of the study was to determine the vertical transmission of COVID-19 infection in COVID-19 positive obstetrical patients by comparing amniotic fluid and immediate neonatal COVID-19 RT-PCR. 


\section{Objectives}

The objectives of this study were (a) to estimate the incidence of COVID-19 in amniotic fluid of COVID positive obstetrical patients delivering in our institution; and (b) to estimate the incidence of COVID-19 in neonates in COVID positive mothers delivering in our institution.

\section{METHODS}

\section{Study design}

The study design was hospital based prospective study.

\section{Place of study}

The study was carried out at department of pediatrics; and obstetrics and gynaecology, Muzaffarnagar Medical College and Hospital.

\section{Study population}

All admitted COVID positive delivery patients were the study population.

\section{Duration}

The study duration was of six months from April 2020 to January 2021.

\section{Sample size}

The sample size was 50 .

\section{Sampling technique}

All COVID positive deliveries occurring in our institution in study duration fulfilling inclusion and exclusion criteria.

\section{Statistical analysis}

Suitable statistical significance test that were used for statistical analysis with SPSS 25.0 software. The $\mathrm{p}$ value less than 0.05 was considered statistically significant.

\section{Inclusion criteria}

All inborn COVID positive deliveries were included.

\section{Exclusion criteria}

Patients with following criteria were excluded- (a) all inborn Non COVID deliveries; and (b) all outborn deliveries.

\section{Method of data collection}

Our hospital is a tertiary care centre, one wing of this hospital was converted into COVID hospital since April
2020.This wing is a 5 storied building which is sealed on both the sides and only COVID patients, COVID doctors and nursing staff and paramedical staff on duty can enter it. First floor was converted into obstetrics and gynecology department which has OT, labor room and separate obstetrics and gynecology ward.

All obstetrics patients who were COVID positive in District Muzaffarnagar were sent to our COVID hospital because in District Muzaffarnagar, ours was the only COVID Hospital, which was treating COVID obstetrics and gynecology patients. All the obstetric COVID patients were given $\mathrm{N} 95$ masks and shield and then examined by doctor wearing PPE kit, N95 masks and face shield. Our labor room and OT are made as negative pressure unit as per COVID guidelines. Firstly, consent was taken about dangers of COVID disease, and for perinatal morbidity and mortality of mother as well as fetus.

Consent was taken about testing of amniotic fluid and neonate immediately after birth (during cesarean as well as vaginal delivery). After admission detailed history was taken from the patient, general and obstetrics examination (per abdomen, per vaginal) was done. All routine investigations were sent to decide if the patient has to be taken up for normal delivery or cesarean section.

All patients were also examined by physician and COVID investigations were sent and management was done accordingly.

\section{Procedure}

During vaginal delivery or caesarean section sample was taken from amniotic fluid and collected in viral transport medium (VTM). Sample was also collected as nasal and oropharynsgeal swab from neonate immediately and sent for RT-PCR.

\section{RESULTS}

This study was carried out in the COVID ward of obstetrics and gynaecology from April 2020 to January 2021. Total 50 COVID-19 positive obstetrics patient deliveries carried out during this time out of which 43 were LSCS and 7 were normal deliveries.

In this study of total 50 cases; 43 neonates were delivered via LSCS and 7 normal; 41 (82\%) neonates were normal; $4(8 \%)$ were IUGR. Out of these 3 were admitted in NICU for respiratory distress, 2 were IUD, 1 was preterm and 1 neonatal death. After the delivery, all the neonates were tested for COVID-19 via RT-PCR through nasopharyngeal swab and all were negative. In this study 48 (96\%) women had no morbidity and were discharged healthy 1 patient (2\%) developed acute kidney failure and 2 patients (4\%) died due to pulmonary embolism. Table 1 shows that maximum patients $(\mathrm{N}=50), 21(42.0 \%)$ were of age group 25-29 years. Most of the patients $(\mathrm{N}=50), 45$ (90\%) were un-booked and $48(96 \%)$ were of third trimester. This 
shows that most of the obstetric patients came to hospital when they developed labour pains and they were tested positive for COVID-19 disease. 48 (96\%) patients were asymptomatic and only $2(4 \%)$ patients had fever and cough. LSCS was done in $43(86 \%)$ patients and normal delivery occurred in $7(14 \%)$ patients. Main indication of LSCS was fetal distress in $16(37.2 \%)$ patients.

Table 2 shows the type of treatment required in these patients. Antibiotic was started in all patients at the time of admission and injection enoxaparin was also given to all the patients but only after delivery to combat the hypercoagulable state of both pregnancy and COVID-19 disease. In other patients, depending on the severity of COVID-HCQ was given in $35(70 \%)$ patients, antiviral treatment $28(56 \%)$ patients and steroids were given in 28 $(56 \%)$ patients. ICU admission was done in $2(4 \%)$ patients who developed severe COVID-19 disease.

Table 3 shows investigations of most of the COVID-19 positive obstetric patients. All the patients showed elevated inflammatory markers. CRP was increased in 40 $(80 \%)$ patients, D-dimer was increased in all $50(100 \%)$ patients. IL-6 was increased in $49(98 \%)$ patients and S. ferritin was increased in $48(96 \%)$ patients. X-ray chest showed changes of pneumonia in $28(56 \%)$ patients in spite of the fact that 48 $(96 \%)$ patients were asymptomatic. Most important investigations were RT-PCR testing of amniotic fluid and immediate testing of RT-PCR of nasal and pharyngeal swab of the neonate to rule out vertical transmission. Surprisingly RT-PCR tests of all the amniotic fluids samples as well as nasal and oropharyngeal samples of neonates were negative in spite of the fact that $2(4 \%)$ of the patients were diagnosed with severe COVID-19 positive disease.

Table 4 shows perinatal and neonatal mortality and morbidity. It shows that 39 neonates (78.08\%) were normal. 4 of them had IUGR. Of total 50 neonates, 2 were admitted to NICU for respiratory distress and 1 admitted for Birth asphyxia. 2 of the neonates were IUD due to abruptio placentae and fetal distress due to obstructed labour. $2(4 \%)$ of the 50 neonates were pre-term. Out of all 50 neonates there was only $1(2 \%)$ neonatal death. Table 5 shows maternal morbidity and mortality. It shows that 48 women $(96 \%)$ had no morbidity and were discharged healthy. 1 patient ( $2 \%$ ) developed acute kidney failure and 2 patients (4\%) died due to pulmonary embolism.

Table 1: Clinical characteristics.

\begin{tabular}{|c|c|c|}
\hline Clinical characteristics & No. of patients $(\mathrm{N}=50)$ & Percentage $(\%)$ \\
\hline \multicolumn{3}{|l|}{ Age of patients (years) } \\
\hline $20-24$ & 20 & 10 \\
\hline $25-29$ & 21 & 42 \\
\hline $30-34$ & 7 & 14 \\
\hline $35-39$ & 2 & 4 \\
\hline \multicolumn{3}{|l|}{ Booking status of the patients } \\
\hline Booked & 5 & 10 \\
\hline Un-booked & 45 & 90 \\
\hline \multicolumn{3}{|l|}{ POG of the patients } \\
\hline$<37$ weeks & 2 & 4 \\
\hline$\geq 37$ weeks & 48 & 96 \\
\hline \multicolumn{3}{|l|}{ Gravida of the patients } \\
\hline Primigravida & 18 & 36 \\
\hline Multigravida & 32 & 64 \\
\hline \multicolumn{3}{|c|}{ Symptoms of COVID-19 at presentation } \\
\hline Asymptomatic & 48 & 96 \\
\hline Cough & 2 & 4 \\
\hline \multicolumn{3}{|l|}{ Mode of delivery } \\
\hline LSCS & 43 & 86 \\
\hline NVD & 7 & 14 \\
\hline \multicolumn{3}{|l|}{ Indications for LSCS } \\
\hline Fetal distress & 16 & 37.2 \\
\hline Scar tenderness & 10 & 23.2 \\
\hline Pre-eclampsia & 6 & 13.9 \\
\hline Post-dated pregnancy & 4 & 9.3 \\
\hline Previous 2 LSCS with pain abdomen & 3 & 6.9 \\
\hline Previous 3 LSCS with pain abdomen & 1 & 2.3 \\
\hline Oligohydramnios & 2 & 4.6 \\
\hline Malpresentation & 1 & 2.3 \\
\hline
\end{tabular}


Table 2: Clinical characteristics.

\begin{tabular}{|lll|}
\hline Types of treatments & No. of patients $(\mathbf{N}=\mathbf{5 0})$ & Percentage $(\%)$ \\
\hline Antibiotic & 50 & 100 \\
\hline HCQ & 35 & 70 \\
\hline Injection enoxaparin & 50 & 100 \\
\hline Antiviral treatment & 28 & 56 \\
\hline Use of steroid & 28 & 56 \\
\hline
\end{tabular}

Table 3: Lab investigations.

\begin{tabular}{|c|c|c|}
\hline Lab investigations & No. of patients & Percentage (\%) \\
\hline \multicolumn{3}{|l|}{ Blood investigations } \\
\hline \multicolumn{3}{|l|}{ Level of CRP } \\
\hline Above the normal limit & 40 & 80 \\
\hline Within the normal limit & 10 & 20 \\
\hline \multicolumn{3}{|l|}{ D-dimer } \\
\hline Above the normal limit & 50 & 100 \\
\hline Within the normal limit & 0 & 0 \\
\hline \multicolumn{3}{|l|}{ IL-6 } \\
\hline Above the normal limit & 49 & 98 \\
\hline Within the normal limit & 1 & 2 \\
\hline \multicolumn{3}{|l|}{ Serum ferritin } \\
\hline Above the normal limit & 48 & 96 \\
\hline Within the normal limit & 2 & 4 \\
\hline \multicolumn{3}{|l|}{ Chest X-ray } \\
\hline Above the normal limit & 28 & 56 \\
\hline Within the normal limit & 22 & 44 \\
\hline \multicolumn{3}{|c|}{ RT-PCR of amniotic fluid } \\
\hline Negative & 50 & 100 \\
\hline Positive & 0 & 0 \\
\hline \multicolumn{3}{|c|}{ Immediate RT-PCR testing of nasal and pharangeal swab of neonate } \\
\hline Negative & 50 & 100 \\
\hline Positive & 0 & 0 \\
\hline
\end{tabular}

Table 4: Perinatal and neonatal mortality and morbidity.

\begin{tabular}{|lll|}
\hline Outcomes & No. of patients & Percentage (\%) \\
\hline Normal & 41 & 82 \\
\hline IUGR & 4 & 8 \\
\hline IUD & 2 & 4 \\
\hline Pre-term & 2 & 4 \\
\hline Neonatal death & 1 & 2 \\
\hline
\end{tabular}

Table 5: Maternal morbidity and mortality.

\begin{tabular}{|lll|}
\hline Outcome of patients & No. of patients & Percentage $(\%)$ \\
\hline Discharged alive & 48 & 96 \\
\hline Died during treatment & 2 & 4 \\
\hline Maternal morbidity & 1 & 2 \\
\hline
\end{tabular}

\section{DISCUSSION}

Total of 50 COVID positive patients were delivered during study, out of which 43 were LSCS and 7 were normal deliveries. Most of the patients were in the age group 2530 and all were unbooked and in third trimester. Similar observation was seen by Shah et al in there study of
COVID-19 pregnant women in 2020 with mean age group of 21-30 years. ${ }^{1}$

All the patients were started on injection enoxaparin and antibiotics postoperatively. HCQ was started in $35(70 \%)$ patients, antiviral in $28(50 \%)$ and steroids in $28(56 \%)$ patients. 
2 were admitted in ICU due to very severe COVID. ${ }^{1}$

In spite of the fact that 48 (96\%) patients were asymptomatic, CRP, D-dimer, IL6 and S. ferritin were carried out in all the patients. CRP was increased in 40 (80\%), D-dimer in 50 (100\%), IL-6 in 49 (98\%) and S. ferritin in $48(96 \%)$ of the patients. Chest X-ray shows pneumonia in $28(58 \%)$ cases. $^{1}$

Asymptomatic patients were $38.4 \%$ in a study by Shah et al in 2020. While our study had $96 \%$ patients asymptomatic. This may be due to the fact that massive testing and tracing was done during that period especially in COVID-19 obstetrical patients and this is one of the factor in decreasing perinatal maternity and mortality in our study. They also noted increased $\mathrm{C}$-reactive protein in $2 / 3$ rd cases and $52 \%$ showed haziness and opacity in chest $\mathrm{X}$-rays. Our study also showed increased CRP and chest haziness in 58\% of cases and this is in accordance with our study. Our main aim was to find out vertical transmission in this study. So, in all the patients RT-PCR of amniotic fluid and immediate testing of RT-PCR of nasal and pharyngeal swab of neonates was done. We were amazed to know that none of the samples came out to be positive. ${ }^{1}$

Shah et al also studied vertical transmission and their results indicated that $16.67 \%$ neonates at birth were positive suggesting the possibility of vertical transmission which is not according to our study. ${ }^{1}$

Claudia Fenizia from university of Milan, Italy in 2020 also analysed SARS-CoV-2 vertical transmission in 31 obstetric patients and studied viral genome on maternal and new born nasopharyngeal swab, vaginal swabs, maternal and umbilical cord plasma, placenta and umbilical cord biopsies, amniotic fluid and milk from 31 mothers. It was found that viral genome was positive in 1 patient of umbilical cord blood, 2 patients in placenta, 1 patient in vaginal mucosa, 1 patient of milk specimen and vertical transmission was positive in 3 neonates. They also reported the presence of specific SARS-Cov-2 IgM And IgG antibodies in 1 umbilical cord blood and 1 milk specimen. So these data support the hypothesis that in utero SARS-Cov-2 vertical transmission, while low is possible which is slightly different from our study. ${ }^{2}$

Facchetti et al from University of Brescia, Italy in 2020 also studied placenta from 15 women who tested positive for SARS-CoV-2 RNA by RT-PCR and found single placenta tested positive for SARS-CoV-2 proteins. Immunophenotyping showed heterogenous composition of inflammatory cells mostly monoctyes, macrophages and neutrophils. This provides evidence in support of transmission of SARS-CoV-2 infections from COVID-19 full term pregnant women to her newborn who resulted positive for SARS-CoV-2 and developed pneumonia soon after birth. ${ }^{3}$

Flannery et al from University of Pennsylvania in 2020 studied maternal and neonatal cord blood SARS-CoV-2 antibodies in 1714 parturient women and SARS-CoV-2 $\mathrm{IgG}$ and IgM antibodies in cord blood of 83 neonates at the time of delivery and these findings demonstrate the potential for maternally derived SARS-CoV-2 specific antibodies to provide neonatal protection from corona virus disease. $^{4}$

In a study of recommendations of perinatal and neonatal management of COVID-19 infection 707 neonates were studied born to COVID-19 positive women, 111 (15.7\%) were admitted in NICU, 20 had pneumonia and 3 died. Vertical transmission was suspected in 17 neonates $(2.4 \%)$ based on virologic and serological reports. ${ }^{5-8}$

Of the 17 neonates with suspected vertical transmission, infection was confirmed by positive RT-PCR in 11. In 3 neonates' infection was suspected based on elevated antiCOVID-19 IgM and IgG levels at birth. In another 3 neonates only, IgG levels were elevated. In these 6 neonates with elevated antibodies, RT-PCR was repeatedly negative indicating possibility of intrauterine infection of the fetus. ${ }^{9,10}$

Neonates is said to be exposed to COVID-19 if they are born to mother with history of COVID-19 infection diagnosed from 14 days before delivery upto 28 days after delivery or if the neonate is directly exposed to close contact with COVID-19 infection.

There are three modes of mother to baby transmission of COVID-19 as follows:

\section{Intrauterine transmission}

It is considered when nasopharyngeal or amniotic fluid or cord blood or neonatal blood RT-PCR is positive at less than 24 hour and persistence of nasopharyngeal RT-PCR positive at more than equal to 24 to 48 hour and IgM positive during week $1 .^{11}$

\section{Intrapartum or immediate postnatal transmission}

It is considered when RT-PCR negative less than 24 hour but positive 1-14 days after birth and IgM positive at 2-3 weeks. ${ }^{11}$

\section{Postnatal transmission}

It is considered when nasopharyngeal or amniotic fluid or cord blood or neonatal blood RT-PCR positive at less than 24 hour and no evidence of persistence as nasopharyngeal RT-PCR negative at more than equal to 24 to 48 hour and IgM positive during week 2 week after birth. ${ }^{11}$

In our study there were 39 LSCS and 7 normal deliveries so the risk of intrauterine transmission is there for which we had taken neonatal nasopharyngeal and amniotic fluid is highest, as the rooming-in and breastfeeding was not done as the neonates were immediately handed over to attendants so the risk of postnatal transmission from 
mother was less. We have not taken follow up samples from the neonate so there is less data about postnatal COVID-19 transmission.

\section{Limitations}

At this time there was limited evidence on the extent of SARS-CoV-2 vertical transmission and its timing due to limitations related to the sensitivity and specificity of diagnostic testing, and lack of collection of appropriate specimen at appropriate time. Small sample size of only 50 cases. A follow up study of larger sample may be required.

\section{CONCLUSION}

This notorious virus has travelled the whole world right from China to Asia to Europe to Australia and New Zealand. The virus has travelled all the continents and has not spared anybody. But it is an amazing and pleasant surprise that virus is not able to do much harm to foetus despite the fact that foetus is separated from mother by very thin placental barrier. This is the miracle of god protecting the foetus. Many studies are done to study the vertical transmission, the low vertical transmission maybe due to the fact that antibodies are produced by the mother that crosses the placenta and saves the foetus or there are highly specific immunological mediators in the placenta that do not allow the infection to pass to the foetus. So, this vertical transmission and placental barrier requires further research and studies.

\section{Funding: No funding sources}

Conflict of interest: None declared

Ethical approval: The study was approved by the Institutional Ethics Committee

\section{REFERENCES}

1. Shah PT, Shah SR, Shah SR, Yadava PA. Fetomaternal outcome in COVID-19 infected pregnant women: a preliminary clinical study. Int $\mathbf{J}$ Reprod Contracept Obstet Gynecol. 2020;9(9):370410.

2. Fenizia C, Biasin M, Cetin I, Vergani P, Mileto D, Spinillo A, Gismondo MR, et al. Analysis of SARS-
CoV-2 vertical transmission during pregnancy. Nat Commun. 2020;11(1):5128.

3. Facchetti F, Bugatti M, Drera E, Tripodo C, Sartori E, Cancila V, et al. SARS-CoV2 vertical transmission with adverse effects on the newborn revealed through integrated immunohistochemical, electron microscopy and molecular analyses of Placenta. EBioMedicine. 2020;59:102951.

4. Flannery DD, Gouma S, Dhudasia MB, Mukhopadhyay S, Pfeifer MR, Woodford EC, et al. JAMA Pediatr. 2021;175(6):594-600.

5. Carosso A, Cosma S, Borella F, Marozio L, Coscia A, Ghisetti V, et al. Pre-labor anorectal swab for SARSCoV-2 in COVID-19 pregnant patients: is it time to think about it? Eur J Obstet Gynecol Reprod Biol. 2020;249:98-9.

6. Zamaniyan M, Ebadi A, Aghajanpoor S, Rahmani Z, Haghshenas M, Azizi S. Preterm delivery, maternal death, and vertical transmission in a pregnant woman with COVID-19 infection. Prenat Diagn. 2020;40(13):1759-61.

7. Alzamora MC, Paredes T, Caceres D, Webb CM, Valdez LM, Rosa M. Severe COVID-19 during Pregnancy and Possible Vertical Transmission. Am J Perinatol. 2020;37(8):861-5.

8. Zeng L, Xia S, Yuan W, Yan K, Xiao F, Shao J, et al. Neonatal Early-Onset Infection With SARS-CoV-2 in 33 Neonates Born to Mothers With COVID-19 in Wuhan, China. JAMA Pediatr. 2020;174(7):722-5.

9. Zeng H, Xu C, Fan J, Tang Y, Deng Q, Zhang W, et al. Antibodies in Infants Born to Mothers With COVID-19 Pneumonia. JAMA. 2020;323(18):18489.

10. Dong L, Tian J, He S, Zhu C, Wang J, Liu C, et al. Possible Vertical Transmission of SARS-CoV-2 From an Infected Mother to Her Newborn. JAMA. 2020;323(18):1846-8.

11. Buonsenso D, Costa S, Sanguinetti M, Cattani P, Posteraro B, Marchetti S, et al. Neonatal Late Onset Infection with Severe Acute Respiratory Syndrome Coronavirus 2. Am J Perinatol. 2020;37(8):869-72.

Cite this article as: Tyagi S, Agarwal RK, Agrawal M, Kapoor M, Tiwari S. Study of vertical transmission of COVID-19 infection in COVID-19 positive obstetrical patients by comparing amniotic fluid and immediate neonatal COVID-19 RT-PCR. Int J Reprod Contracept Obstet Gynecol 2021;10:3383-8. 